\title{
The Use of Ultrasonic Cleaning for Ultrafiltration Membranes in the Dairy Industry
}

\author{
S. Muthukumaran ${ }^{\mathrm{a}}$, K. Yang ${ }^{\mathrm{a}}$, A. Seuren ${ }^{\mathrm{a}}$, S. Kentish*, M. Ashokkumar ${ }^{\mathrm{b}}$, G. W \\ Stevens ${ }^{\mathrm{a}}$, F. Grieser ${ }^{\mathrm{b}}$ \\ ${ }^{a}$ Department of Chemical and Biomolecular Engineering \\ ${ }^{b}$ School of Chemistry \\ The University of Melbourne, Melbourne, Vic 3010, Australia
}

\begin{abstract}
The ultrafiltration of whey solutions is a common feature of dairy processes. However, the frequent fouling of ultrafiltration membranes and the subsequent cleaning cycle significantly affects the economics of such a process. In this work, we investigated the effect of ultrasonics on the cleaning of whey-fouled membranes and examined the variables that influence this effect. Experiments were conducted using a small single sheet membrane unit that was immersed totally within an ultrasonic bath.

Results show that the use of ultrasonics enhances the flux recovery following fouling. The extent of flux recovery is independent of the length of sonication time and increases with ultrasonic power. The use of surfactants in combination with ultrasonic irradiation shows a synergistic effect, providing a better efficiency than either cleaning process alone. Repetitive use of ultrasonic cleaning over a one month period does not result in any significant change in the permeate flux of a cleaned membrane, indicating that the ultrasonic treatment does not appear to damage the membrane structure itself.
\end{abstract}

Keywords: ultrafiltration; dairy; ultrasonics; membrane cleaning; whey processing

\section{Introduction}

Membrane separation in general and ultrafiltration in particular is frequently employed in the dairy, paint, biochemical, and pharmaceutical industries. In the dairy industry, ultrafiltration is used for the concentration of whey, a protein by-product of cheese making which otherwise creates pollution and disposal problems. During the ultrafiltration process, the membranes foul over time, as the retained particles accumulate on the membrane surface. Fouling results in a significant reduction in the separation efficiency by decreasing the permeate flux and increasing the pressure drop across the membrane. In the dairy industry, the membranes used for the ultrafiltration of whey are cleaned and sanitised after each batch of processing in order to increase the life span of the membrane, to ensure hygienic operation, to maintain membrane performance and to reduce the cost for membrane replacement. Therefore, membrane cleaning is an essential step in maintaining the membranes used for the separation process [1].

*Corresponding Author. Email Address: sandraek@unimelb.edu.au 
There are a number of different chemical and physical cleaning methods currently used for membrane cleaning in industry. Chemical processes consume large volumes of expensive chemicals such as surfactant and caustic soda which can themselves damage the membrane material and in turn reduce the life span of the membrane. Physical cleaning methods like backflushing and backwashing are also used to clean the fouled membranes. However, these techniques interrupt the continuous filtration process leading to a longer processing time.

Power ultrasound in the $\mathrm{kHz}$ range has found wide application in general industry for cleaning and has proved to be extremely efficient for this purpose. It is more effective than any other method that does not mechanically abrade the base material of the surface or chemically dissolve it. Ultrasonic energy can be used as a cleaning agent because it may cause erosion, disperse a solid or liquid film and/or increase the rate at which a surface film is dissolved [2]. It can reach crevices that are not easily reached by conventional methods [3].

Such sonication has been suggested as a possible tool for cleaning membranes in the dairy industry in order to reduce the reliance on chemicals and the problems encountered in physical cleaning methods. Sonication will cause agglomeration of fine particles and supply sufficient agitation energy to the system to keep these particles partly suspended. This leaves more free channels for solvent elution [3]. Cavitation phenomena produced by the ultrasonic wave may also help to displace the cake on the membrane structure [4$6]$ which in turn promotes fouling prevention and facilitates improved separation rates [7 $-9]$.

In the present study, our objective is to investigate the effect of ultrasound on the cleaning of polymeric ultrafiltration membranes fouled by dairy whey solution, under various operating conditions. The results of this investigation are discussed in this paper.

\section{Experimental}

\subsection{Experimental set up}

The experimental set-up for this study is shown in Figure 1. A polysulfone (PS) flat sheet ultrafiltration membrane with a molecular weight cut off of 30,000 and an effective membrane area of $30 \mathrm{~cm}^{2}$ was used to study cross flow filtration in a Minitan S unit. (Millipore, Inc.). The membrane $(15 \times 11 \mathrm{~cm})$ was placed between two acrylic manifolds of thickness $2.3 \mathrm{~cm}$ which were in turn held in place by stainless steel plates of $1.1 \mathrm{~cm}$ thickness. Perforated silicone separators of approximately $1 \mathrm{~mm}$ thickness were placed between the membrane and each manifold in order to create a series of linear flow channels. The assembled membrane unit was placed inside the membrane holder, which was immersed in the water bath $\left(29.5 \times 24 \times 20 \mathrm{~cm}^{3}\right)$ of a sonicator (Ultrasonics, Sydney Australia, Model FXP14DH, frequency: 50kHz; output power: $300 \mathrm{~W})$. 
A peristaltic pump (Master flex ${ }^{\mathrm{R}}$ 96400-18) was used to pump the feed solution through the crossflow ultrafiltration unit at $600 \mathrm{ml} /$ min with a transmembrane pressure of $55 \mathrm{kPa}$. Whey solution of $6 \% \mathrm{w} / \mathrm{w}$ concentration was used to foul the membrane. This whey solution was reconstituted from deionised water and spray dried non-hygroscopic whey powder (donated by Murray Goulburn Co-op Co. Ltd.). Milli-Q water was used to make up all process solutions throughout the study. The surfactant, sodium dodecyl sulfate (SDS, 95\%, Scharlau Chemie) was used as a cleaning agent. The $\mathrm{pH}$ of the SDS solution was adjusted in the range $7-10$ using $0.5 \mathrm{M} \mathrm{NaOH}$. The feed temperature was maintained between $20-22^{\circ} \mathrm{C}$. The permeate flux was determined by a weight measuring method using an electronic balance.

\subsection{Experimental Procedure}

Initially the pure water permeate flux was measured and this value was used as a reference for the membrane permeability. Subsequently, the membrane was fouled for between 10 and 30 minutes with freshly prepared 6\% w/w whey solution and the permeate rate was measured. After fouling, Milli-Q water was fed through the ultrafiltration unit and the water flux was measured. The ultrafiltration unit was then placed into the sonication bath and sonicated for a specified time ( 0 to 30 minutes), with Milli-Q water continuing to circulate over the membrane. Some experiments were also carried out with circulating surfactant solution. The bath water was replaced as necessary to maintain the temperature in the range, $22-25^{\circ} \mathrm{C}$. After sonication, the ultrafiltration unit was removed from the sonication bath. Milli-Q water was again fed through the unit and the final water permeate flux recorded.

The membrane was cleaned between experiments by circulating $0.1 \mathrm{M}$ sodium hydroxide for 10 minutes. The membrane was then left to soak in this solution for 30 minutes. After 30 minutes, Milli-Q water was fed into the unit to flush out the cleaning solution. A further permeate water flux was recorded and compared to the initial water flux. If there was a significant discrepancy between these values, or if the retentate flow remained cloudy, the cleaning process was repeated. When not in use, the membrane was stored in Milli-Q water, which was replaced regularly.

\section{Results}

A series of experiments were conducted to study the effects of the following experimental conditions on the membrane cleaning process:

- Sonication time.

- Fouling time.

- Surfactant concentration.

- Power level of the transducer. 


\subsection{Permeate flux change of polysulfone membrane (PS) by ultrasound treatment}

To assess if sonication affects the intrinsic permeability of the membrane, the water permeate flux after sonication was observed. The results shown in Figure 2 indicate that the permeate flux for water was constant irrespective of ultrasonic irradiations. This observation is consistent with early reports $[4,5,7,9]$ and confirms that the ultrasound irradiation does not influence the intrinsic permeability of the PS membrane.

Figure 3 shows the average water permeate flux through cleaned membranes at the start of each day's experiments following soaking in water overnight. The plot shows that there is no trend in this value over time, suggesting that ultrasound treatment has not damaged the PS membrane, which is consistent with the results observed in Figure 2. If the membrane was damaged during prolonged use over a period of time, then it could be expected that the permeate flux would increase due to the increase in pore size of the membrane resulting from the cavitation damage of the membrane.

This is contrary to the results of Masselin et al.[6] who indicated that polyethersulfone (PES) membranes could be damaged after as little as 5 minutes exposure at $47 \mathrm{kHz}$. In this work the membrane material was placed directly in the ultrasonic bath simply in a beaker of water. The bath power is not reported. Hence, it is possible that power levels reaching the membrane in this case were much higher. More importantly, in the work of Masselin et al.[6] there is no cross-flow across the membrane. In a stagnant environment it is possible for a cavitation bubble to become trapped at a point on the membrane surface and physically erode the surface by repeated oscillations at this point. Such a failure mechanism fits with the discussion of membrane damage reported in this paper. The presence of a cross-flow during ultrasonic radiation reduces the likelihood of such an event occurring.

\subsection{Effect of sonication time on permeate flux}

Figure 4 shows the effect of sonication on membrane permeate flux for a fixed fouling time of 20 minutes. This figure shows the different stages of fouling and cleaning throughout a run. The experimental error associated with any permeate flux measurement was estimated as $\pm 0.25 \times 10^{-5} \mathrm{~m}^{3} / \mathrm{m}^{2} \mathrm{~s}$.

During fouling the membrane whey flux decreased with time, when compared to the clean membrane water flux due to the deposition of the protein layer. When the fouled membrane was flushed with water alone without sonication, the permeate water flux increased slightly. This is due to loosely bound proteinaceous material being removed from the membrane surface. After sonication, this water flux increased further because the ultrasound dislodged more tightly bound material from the surface. This may be due to the cavitation phenomena during sonication causing the cake to be physically disrupted. Kobayashi et al.[4] reported that the enhanced permeability during sonication may be due to cavity disruption in water. Sonication may also affect the interaction between individual protein or lactose molecules, further enhancing the cleaning effect. It is reported that ultrasound can be used to separate physical aggregates of such molecules by disrupting the inter-molecular forces. [8]. 
For each experiment, average flux rates were determined by taking a linear average over the data for the last five minutes of each process step. Two parameters were determined from these average flux rates. That is:

Flux recovery $=\frac{\text { Water flux after sonication }}{\text { Clean membrane water flux }}$

The flux recovery parameter represents the overall ability of the cleaning process to restore the original clean membrane flux. However, it can be prone to variability as it encompasses the combined effects of fouling, water flushing and sonication. In particular, it was found that the initial water flux displayed significant variability within each experimental day. As discussed above, for practical reasons, it was necessary to remove the membrane from the membrane holder at night and store this in a solution of Milli-Q water. This meant that the initial water flux at the beginning of each day tended to be higher than values taken for subsequent runs during the day, as the membrane had been soaked for a much longer period.

Conversely, the flux improvement specifically evaluates the improvement in flux rate arising from the sonication step. That is:

Flux improvement $=\frac{\text { Water flux after sonication }- \text { Water flux after fouling }}{\text { Water flux after fouling }}$

Table 1 shows the percentage of flux recovery and flux improvement as a function of sonication time for a constant fouling time of 20 minutes. The result shows that sonication for 10 minutes improves the permeate flux relative to the base case. However, an increase in the sonication time from 10 to 30 minutes had no further effect on improving the flux parameters. It appears that almost all of the ultrasonic effect occurs in the first 10 minutes. This is an extremely important result, as it implies that short bursts of ultrasonic power can be used as a cost-effective method of cleaning.

\subsection{Effect of fouling time on permeate flux}

Table 2 shows the percentage of flux recovery and flux improvement of PS membrane for $6 \%$ whey solution with different fouling times but with a constant sonication time of 10 minutes. An increase in fouling time from 10 to 30 minutes results in no significant change in either flux recovery or flux improvement.

\subsection{Effect of surfactant addition on the permeate flux}

Surfactants are commonly used as detergents and as cleaning agents. In order to investigate whether addition of surfactants influence the ultrasonic flux recovery, a small 
amount of sodium dodecyl sulfate (SDS) was used. This is an anionic surfactant, which is only expected to remove proteins and not minerals.

Figure 5 shows the results of a typical experiment utilising surfactant. The presence of surfactant tends to decrease the permeate flux during its use, but provides a net improvement in the permeate flux of pure water after use. Table 3 shows the effects on permeate flux both with and without SDS. Experiments were done with a constant fouling and sonication time of 20 minutes. The result shows that the presence of surfactant increased the effectiveness of the ultrasonic clean, yielding high flux recovery and flux improvement compared with the no surfactant case. More importantly, the flux improvement was higher for when surfactant was used in combination with ultrasound, than when either was used individually. The surfactant and the ultrasound acted synergistically.

This is probably the result of increased cavitation activity occurring in the more surfaceactive solution [2]. A higher flux recovery was also obtained when $15 \mathrm{mM}$ SDS was used compared to $2 \mathrm{mM}$ SDS at $\mathrm{pH} 7$. This is consistent with earlier reported observations [10].

\subsection{Effect of ultrasonic power level on the permeate flux}

During the course of the experiment program, the type of base used to support the P/S membrane within the Minitan unit was varied in order to observe the effect on the permeate flux. Type 1 is the standard $11-\mathrm{mm}$ thick stainless steel base supplied with the Minitan unit with this unit suspended $8 \mathrm{~cm}$ from the base of the sonication bath. Type 2 is a perforated aluminum base with the unit suspended in the same location. Type 3 is a perforated aluminum base, which was suspended closer to the transducers, $3 \mathrm{~cm}$ from the base of the sonication bath.

Figure 6 and Table 4 show the effect on flux using different base arrangements with a constant fouling time of 30 minutes and sonication time of 20 minutes. Type 1 used the solid base that is expected to reflect ultrasonic energy leading to the least amount of power reaching the membrane. In Type 2 the perforated base caused the membrane to experience more ultrasonic power. In Type 3 the perforated base was still closer to the sonication bath causing the membrane to experience even more ultrasonic power. The three arrangements led to three different power levels impinging on the membrane lower, medium and high power. The result shows that at higher power levels greater flux recoveries can be obtained which indicates that at higher power levels the cleaning is more effective.

\section{Discussion}

\subsection{Possible mechanisms involved in ultrasonic cleaning}

It can be expected that the increased permeability observed due to sonication may have been effected by the physical process caused by the ultrasound. Passing ultrasound 
through a liquid medium leads to an acoustic cavitation - the formation, growth and collapse of microbubbles in the liquid. Mechanical agitation, microstreaming, and the generation of shear forces accompany the process of cavitation. Due to this physical process, which may occur on the surface of the fouled membrane, on the solid material, and in the vicinity of the pores the dislodgement of particles that block the pores can be expected. This may also be accompanied by the break down of these particles. At this stage, with available experimental data, it is difficult to propose if the primary radicals [2] generated during cavitation are also involved in the particle breakdown process.

\subsection{Economic considerations}

For ultrasonic cleaning of ultrafiltration membranes to be a viable option, it must be cost effective. There have been little data presented in the literature addressing this issue. A previous evaluation of ultrasound in a wine filtration plant has indicated that the major operating cost of such a unit is associated with the electricity supply, with a cost of around US \$2000 per year for continuous use of a pilot scale unit [11].

The capital cost associated with transducers and maintenance expenses must also be considered. In an industrial application, ultrasonic transducers would be attached directly to the UF spiral wound modules, so that the ultrasonic energy is applied directly to the processing medium, rather than via water, as in the present experiments. A tunable power supply would control the frequency and power input of the ultrasonic energy.

The current experimental results suggest that a more economic use of ultrasound in dairy ultrafiltration could be achieved by the use of ultrasonic energy intermittently rather than continuously. Firstly, we have shown that short bursts of ultrasound of around 10 minutes can be effective in increasing flux. Consequently, ultrasound might be effective if employed as an intermittent series of short pulses throughout a longer production period. This would reduce the electricity cost to a more viable level. The economic benefits of such a procedure would be an extension in the production time between cleans, thus reducing operating costs. More work is required to further identify the extent to which the production period could be extended.

Secondly, we have shown that surfactants and ultrasound are synergistic in their cleaning effects. Thus, judicious use of ultrasound during a surfactant cleaning cycle could also be cost effective in reducing total chemical consumption. This approach would reduce the purchase cost of cleaning chemicals and also reduce the quantity of waste chemical solutions requiring disposal in an environmentally acceptable manner. A full economic evaluation is planned to determine the practicality of these two options.

\section{Conclusions}

The effect of ultrasound on the permeate flux of fouled polysulfone ultrafiltration membrane was studied using different operating conditions. The results indicate that the ultrasound irradiation does not influence the intrinsic permeability of the membrane or damage the membrane over time. Further the results indicate that the ultrasound 
irradiation is very effective in the removal of protein foulants and so increases the permeate flux after fouling. Sonication time of around 10 minutes appear to be effective with no advantage to be gained in increasing sonication times beyond this value. Further, the use of surfactants in combination with the ultrasound had a synergistic effect, leading to a substantial improvement in the flux recovery. The effectiveness of cleaning can be further improved by increasing the power level reaching the membrane. This suggests that the ultrasound assisted filtration process is a promising technique for preventing membrane fouling during whey treatment in the dairy industry.

\section{Acknowledgments}

Ms Muthukumaran is the recipient of an Australian Post-graduate Award. Financial support for this project has been provided through a University of Melbourne Research and Development Grants Scheme award. This support is gratefully acknowledged.

\section{References}

[1] M. Bartlett, M.R. Bird and J.A. Howell, J. Membrane Sci. 1051995147.

[2] M. Ashokkumar and F. Grieser, Reviews in Chemical Engineering 15199941.

[3] T.J. Mason, L.Paniwnyk and J.P. Lorimer, Ultrasonics Sonochemistry 31996 S253.

[4] T. Kobayashi, T. Kobayashi and F. Nobuyuki, Jpn. J. Appl. Phys. 3920002980.

[5] X. Chai, T. Kobayashi and N. Fujii, Sep. Purif. Technol. 151999139.

[6] I. Masselin, X. Chasseray, L.D. Bourlier, J.M. Laine, J. Membrane Sci. 1812001213.

[7] X. Chai, T. Kobayashi, N. Fujii, J. Membrane Sci. 1481998129.

[8] J. Kost, R.S. Langer, U.S. Patent No. 4780 212, 1988.

[9] T. Kobayashi, X. Chai, N. Fujii, Sep. Purif. Technol. 17199931.

[10] N.D. Lawrence, Ph.D. Thesis, The University of Melbourne, Australia, 1998.

[11] I. Bjorno, L. Bjorno, $17^{\text {th }}$ International Congress on Acoustics, Rome, September 2-7 2001. 
Table 1

Effect of sonication time on permeate flux for a constant fouling time of 20 minutes.

\begin{tabular}{cccccc}
\hline $\begin{array}{c}\text { Sonication } \\
\text { time }\end{array}$ & $\begin{array}{c}\text { Initial } \\
\text { Water Flux }\end{array}$ & $\begin{array}{c}\text { Water Flux } \\
\text { After } \\
\text { Fouling } \\
\mathrm{m}^{3} / \mathrm{m}^{2} . \mathrm{s} \\
\mathrm{x} 10^{5} . \mathrm{s}\end{array}$ & $\begin{array}{c}\text { Water Flux } \\
\text { After } \\
\text { Sonication } \\
\mathrm{m}^{3} / \mathrm{m}^{2} . \mathrm{s} \\
\times 10^{5}\end{array}$ & $\begin{array}{c}\text { Flux } \\
\text { recovery }\end{array}$ & $\begin{array}{c}\text { Flux } \\
\text { improvement }\end{array}$ \\
\hline $0^{1}$ & 3.97 & 1.18 & 0.99 & $25 \%$ & \\
10 & 4.17 & 1.33 & 1.72 & $41 \%$ & $-16 \%$ \\
10 & 2.69 & 0.92 & 1.51 & $56 \%$ & $64 \%$ \\
10 & 3.50 & 1.28 & 1.77 & $50 \%$ & $38 \%$ \\
20 & 4.89 & 1.33 & 1.67 & $34 \%$ & $25 \%$ \\
20 & 3.89 & 1.23 & 1.73 & $45 \%$ & $41 \%$ \\
30 & 3.67 & 0.96 & 1.43 & $39 \%$ & $50 \%$ \\
\hline
\end{tabular}

${ }^{1}$ For this run, the unit was retained in the sonication bath for 10 minutes, but the sonication was turned off.

Table 2

Effect of fouling time on permeate flux for a constant sonication time of 10 minutes

\begin{tabular}{cccccc}
$\begin{array}{c}\text { Fouling } \\
\text { time }\end{array}$ & $\begin{array}{c}\text { Initial } \\
\text { Water Flux }\end{array}$ & $\begin{array}{c}\text { Water Flux } \\
\text { After } \\
\text { Fouling } \\
\mathrm{m}^{3} / \mathrm{m}^{2} . \mathrm{s}\end{array}$ & $\begin{array}{c}\text { Water Flux } \\
\text { After } \\
\text { Sonication } \\
\mathrm{m}^{3} / \mathrm{m}^{2} . \mathrm{s} \\
\mathrm{x} / \mathrm{m}^{2} . \mathrm{s}\end{array}$ & $\begin{array}{c}\text { Flux } \\
\text { recovery }\end{array}$ & $\begin{array}{c}\text { Flux } \\
\text { Min }\end{array}$ \\
$\mathrm{x} 10^{5}$ & 1.31 & 1.98 & $75 \%$ & $51 \%$ \\
10 & 2.64 & 1.14 & 1.84 & $49 \%$ & $61 \%$ \\
10 & 3.78 & 1.33 & 1.72 & $41 \%$ & $29 \%$ \\
20 & 4.17 & 0.92 & 1.51 & $56 \%$ & $64 \%$ \\
20 & 2.69 & 1.28 & 1.77 & $50 \%$ & $38 \%$ \\
20 & 3.50 & 0.81 & 1.39 & $47 \%$ & $71 \%$ \\
30 & 2.94 & & & & \\
\hline
\end{tabular}


Table 3

Effect of surfactant addition on the permeate flux. Fouling time is constant at 20 minutes.

\begin{tabular}{|c|c|c|c|c|c|c|c|}
\hline $\begin{array}{l}\text { Sonication } \\
\text { Time }\end{array}$ & $\begin{array}{l}\text { SDS used } \\
\text { during } \\
\text { sonication } \\
\text { mM }\end{array}$ & $\begin{array}{l}\mathrm{pH} \text { during } \\
\text { sonication }\end{array}$ & $\begin{array}{l}\text { Initial } \\
\text { Water } \\
\text { Flux } \\
\mathrm{m}^{3} / \mathrm{m}^{2} . \mathrm{s} \\
\mathrm{x} 10^{5}\end{array}$ & $\begin{array}{c}\text { Water } \\
\text { Flux } \\
\text { After } \\
\text { Fouling } \\
\mathrm{m}^{3} / \mathrm{m}^{2} . \mathrm{s} \\
\mathrm{x} 10^{5}\end{array}$ & $\begin{array}{c}\text { Water } \\
\text { Flux After } \\
\text { Sonication } \\
\mathrm{m}^{3} / \mathrm{m}^{2} \cdot \mathrm{s} \\
\mathrm{x} 10^{5}\end{array}$ & $\begin{array}{l}\text { Flux } \\
\text { recovery }\end{array}$ & $\begin{array}{c}\text { Flux } \\
\text { improvement }\end{array}$ \\
\hline $0^{1}$ & 0 & 7 & 3.97 & 1.18 & 0.992 & $25 \%$ & $-16 \%$ \\
\hline $0^{1}$ & 2 & 7 & 3.12 & 1.32 & 1.49 & $48 \%$ & $13 \%$ \\
\hline 20 & 0 & 7 & 4.89 & 1.33 & 1.67 & $34 \%$ & $25 \%$ \\
\hline 20 & 0 & 7 & 3.89 & 1.23 & 1.73 & $45 \%$ & $41 \%$ \\
\hline 20 & 2 & 7 & 5.00 & 1.33 & 2.42 & $48 \%$ & $82 \%$ \\
\hline 20 & 2 & 10 & 3.82 & 1.14 & 2.52 & $66 \%$ & $120 \%$ \\
\hline 20 & 15 & 7 & 3.26 & 1.47 & 3.66 & $112 \%$ & $150 \%$ \\
\hline
\end{tabular}

${ }^{1}$ For these runs, the unit was retained in the sonication bath for 20 minutes, but the sonication was turned off. 
Table 4

Effect of different base arrangements on the permeate flux with a constant fouling time of 30 minutes and sonication time of 20 minutes.

\begin{tabular}{|c|c|c|c|c|c|}
\hline Base arrangements & $\begin{array}{l}\text { Initial } \\
\text { Water } \\
\text { Flux } \\
\mathrm{m}^{3} / \mathrm{m}^{2} . \mathrm{s} \\
\mathrm{x} 10^{5}\end{array}$ & $\begin{array}{c}\text { Water } \\
\text { Flux } \\
\text { After } \\
\text { Fouling } \\
\mathrm{m}^{3} / \mathrm{m}^{2} . \mathrm{s} \\
\mathrm{x} 10^{5}\end{array}$ & $\begin{array}{c}\text { Water } \\
\text { Flux After } \\
\text { Sonication } \\
\mathrm{m}^{3} / \mathrm{m}^{2} . \mathrm{s} \\
\mathrm{x} 10^{5}\end{array}$ & $\begin{array}{c}\text { Flux } \\
\text { Recovery }\end{array}$ & $\begin{array}{c}\text { Flux } \\
\text { Improvement }\end{array}$ \\
\hline $\begin{array}{l}1 \text { - Solid base suspended } \\
8 \mathrm{~cm} \text { above transducers }\end{array}$ & 3.89 & 1.23 & 1.59 & $41 \%$ & $29 \%$ \\
\hline $\begin{array}{c}2 \text { - Perforated base suspended } \\
8 \mathrm{~cm} \text { above transducers }\end{array}$ & 3.72 & 1.82 & 2.97 & $80 \%$ & $63 \%$ \\
\hline $\begin{array}{l}3 \text { - Perforated base suspended } \\
3 \mathrm{~cm} \text { above transducers }\end{array}$ & 3.20 & 1.12 & 2.07 & $65 \%$ & $85 \%$ \\
\hline
\end{tabular}




\section{Figure Captions:}

Fig.1. Experimental set-up for ultrasound-assisted cleaning of polymeric membranes in a cross-flow unit. PG represents the pressure gauge.

Fig. 2. Water permeate flux rates at $55 \mathrm{kPa}$ transmembrane pressure and after sonication of unfouled membranes.

Fig. 3. Initial clean membrane water flux at $55 \mathrm{kPa}$ for the first run of each day following cleaning and soaking in water over night.

Fig. 4. Effect of sonication on the flux recovery after fouling for 20 minutes and sonicating for 20 minutes. The Flux recovery is calculated as 34\%, while the Flux improvement is $25 \%$. Note that the periods of zero flux arise due to the delay between permeate entering the line to the balance, and this flow arriving on the balance.

Fig. 5. Effect of 20 minutes of sonication in combination with $2 \mathrm{mM}$ of SDS, after fouling for 20 minutes. The Flux recovery is calculated as $48 \%$ and the Flux Improvement is $82 \%$. Again, note that the periods of zero flux arise from the delay in permeate flow reaching the balance.

Fig. 6. Effect of 20 minutes of sonication at a higher power level, achieved by using a perforated base (Power Level 2). The Flux recovery is calculated as $38 \%$ and the Flux Improvement is $87 \%$. Again, note that the periods of zero flux arise from the delay in permeate flow reaching the balance 
Figure 1

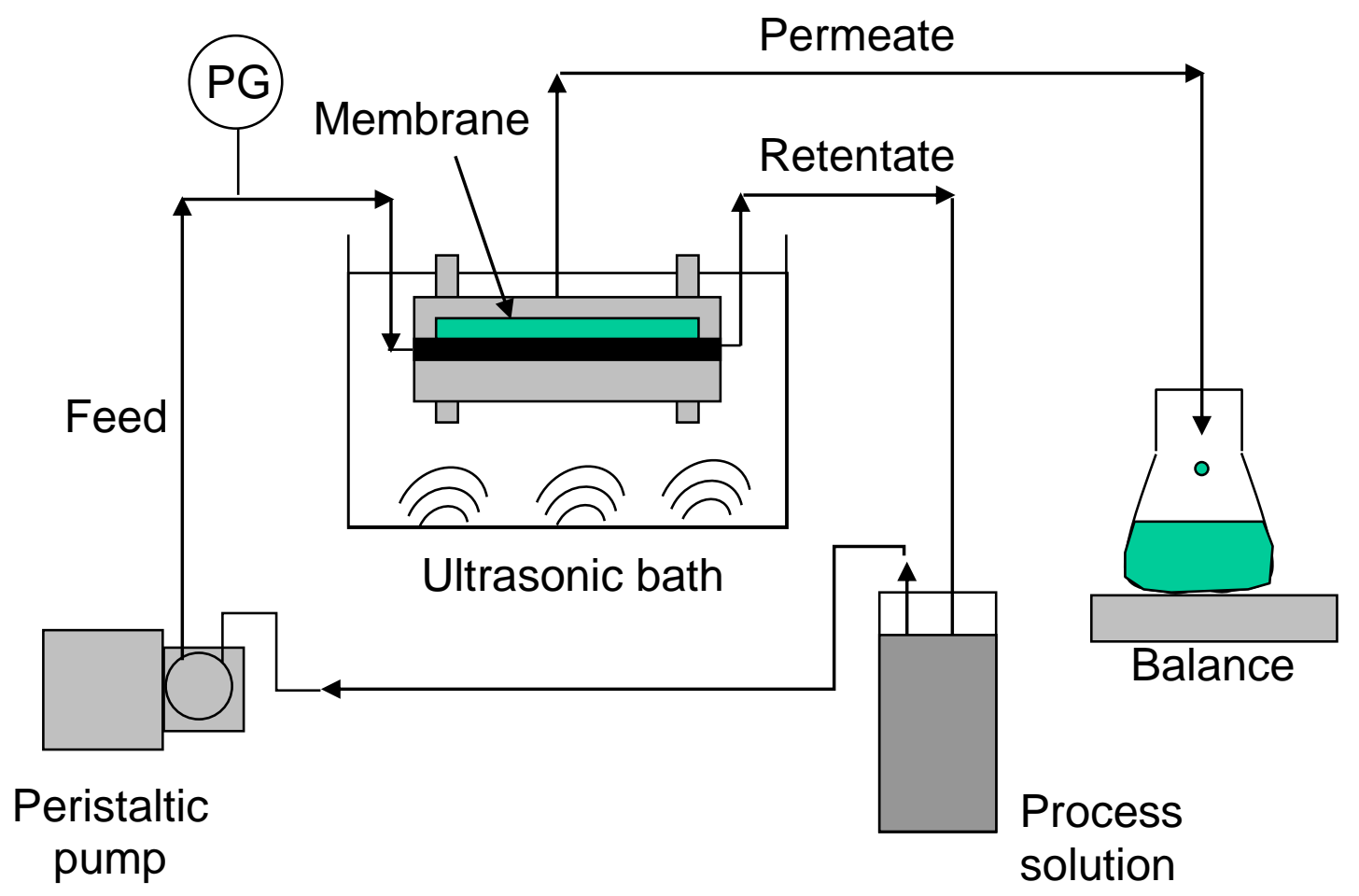


Figure 2

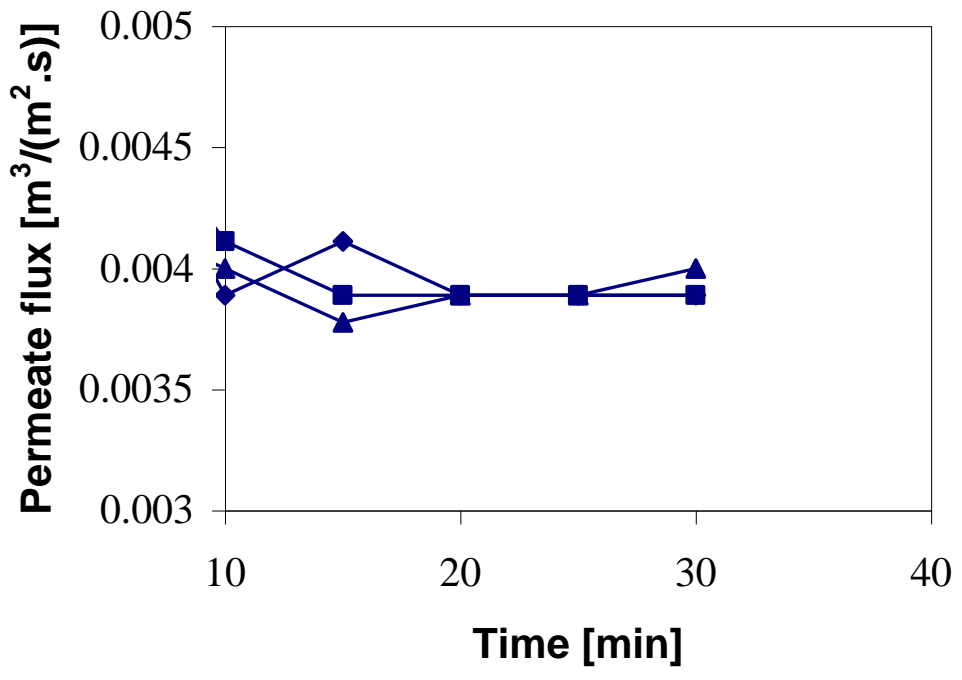


Figure 3

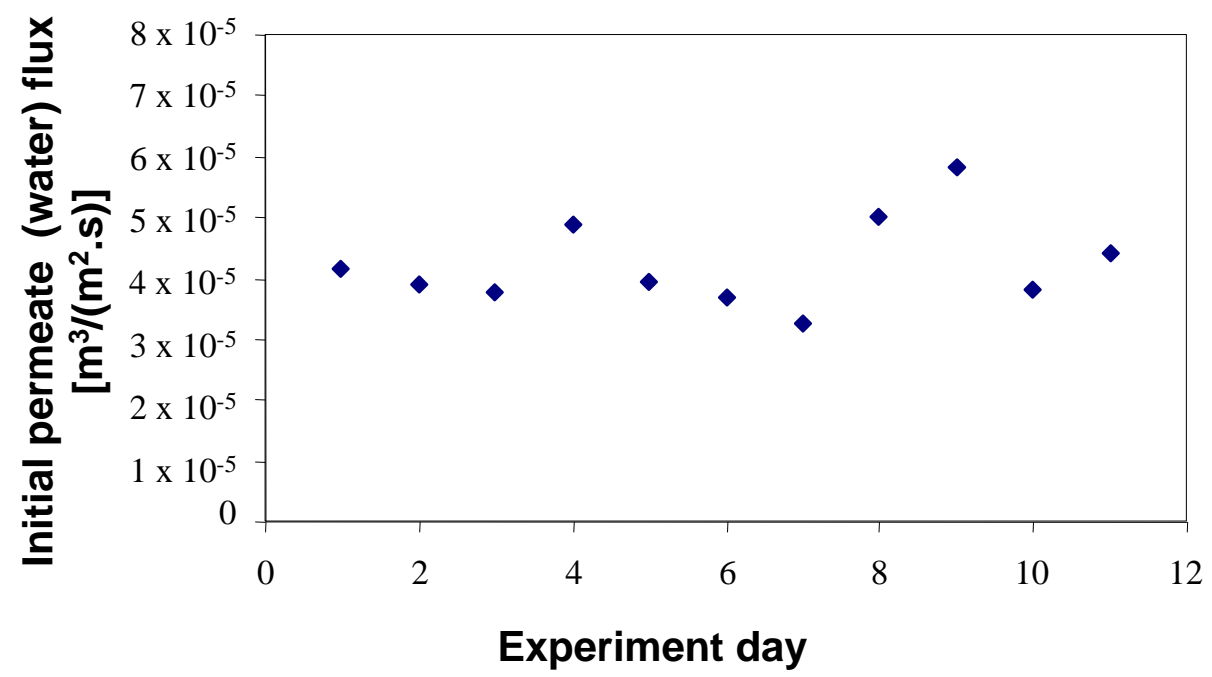


Figure 4

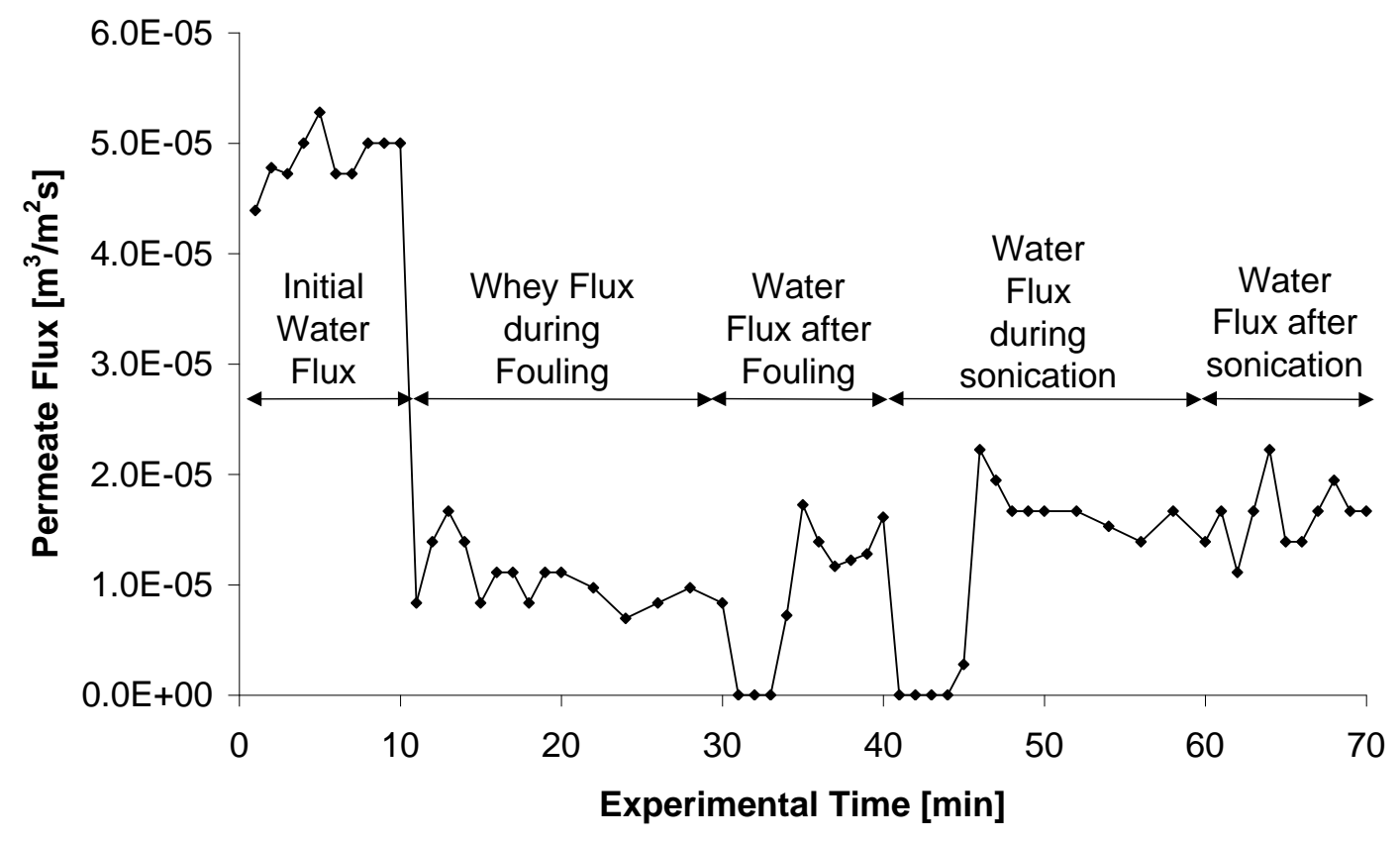


Figure 5

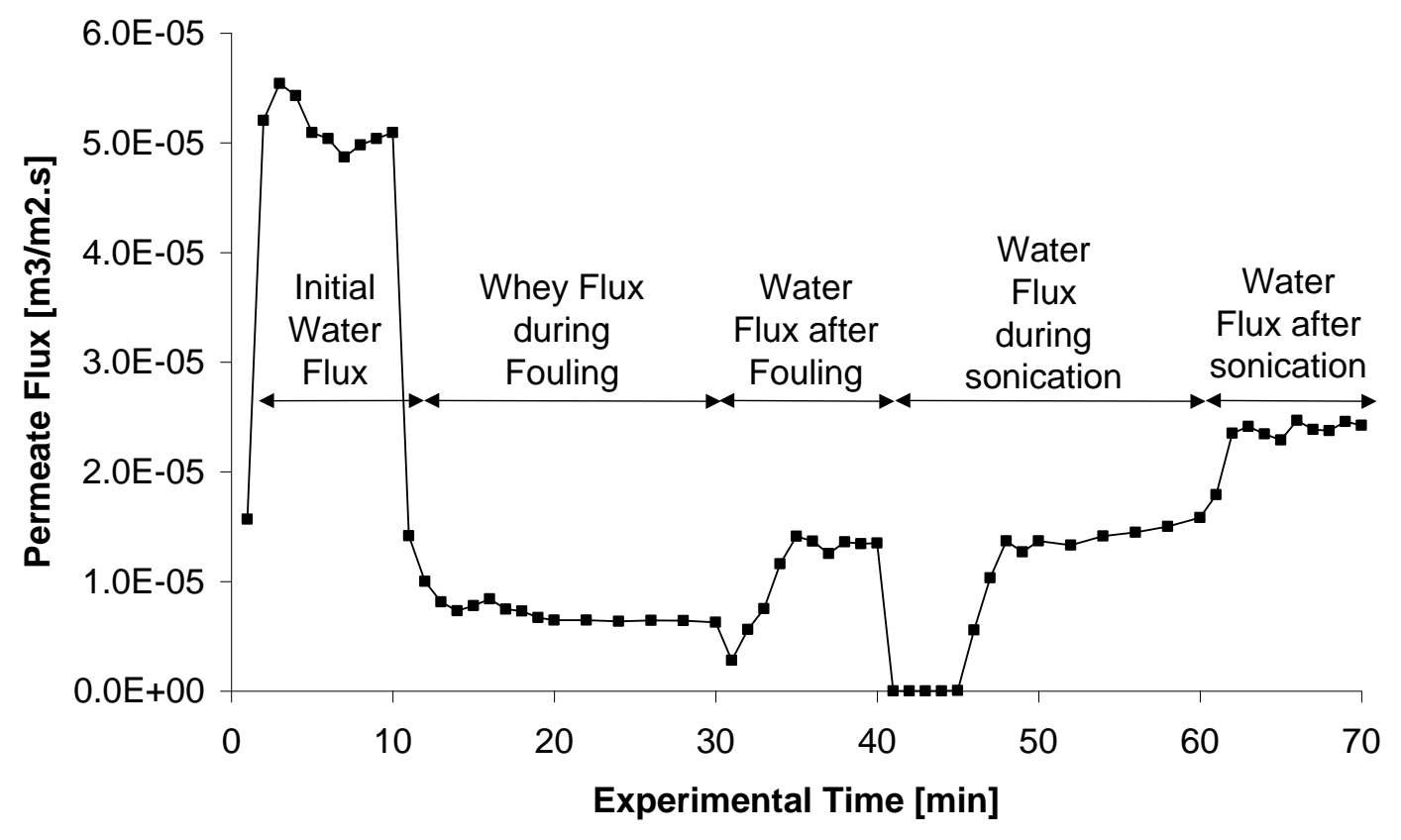


Figure 6

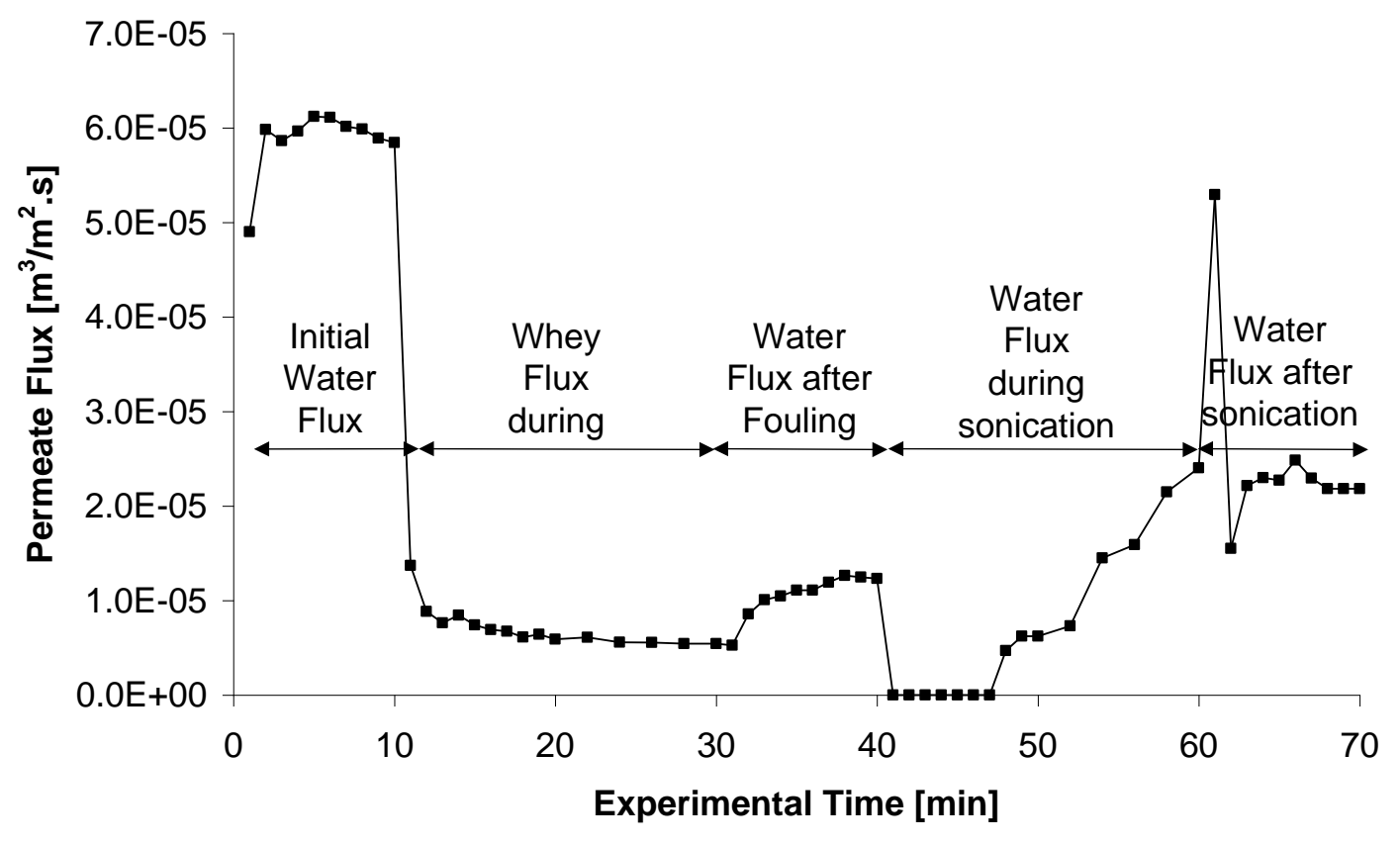

